\title{
Ecophysiological studies of Corophium volutator (Amphipoda) infested by microphallid trematodes
}

\author{
Karin Meißner*, Thomas Schaarschmidt \\ University of Rostock, Department of Zoology, Universitätsplatz 5, 18051 Rostock, Germany
}

\begin{abstract}
The impact of metacercaria infestation on the metabolic activity, thermal tolerance and freezing tolerance of Corophium volutator (Pallas, 1766) was investigated. Metabolic activity was measured by direct microcalorimetry at different temperatures and oxygen conditions. In 2 cases only, at $15^{\circ} \mathrm{C} / 50 \% \mathrm{O}_{2}$ and $10^{\circ} \mathrm{C} / 100 \% \mathrm{O}_{2}$, a positive correlation between infestation intensity and metabolic heat loss was found. At all temperatures examined, hypoxia down to $35 \%$ oxygen saturation did not have a significant effect on metabolic heat loss. With rising temperature, enhanced locomotory activity of $C$. volutator was observed during measurements, but an effect of infestation intensity was not found. According to the results of the thermal tolerance experiments, metacercaria infestation at studied intensities does not compromise infested hosts. In the freezing tolerance experiments, heavily infested C. volutator specimens survived better than specimens with lower infestation intensities. The results indicate a good adaptation of the parasite, because survival of the second intermediate host until consumed by the final host is essential for the completion of the life cycle of digenetic trematodes. It is concluded that under normal field conditions, changes of metabolic activity or reduced tolerance towards thermal stress and freezing as a result of metacercaria infestation should not be responsible for mass mortality events observed in the field. The role of the developmental stage of the metacercaria and the possibly more severe impact caused by not yet or only recently encysted metacercariae, compared to metacercariae with multi-layered cyst walls, is discussed.
\end{abstract}

KEY WORDS: Corophium volutator $\cdot$ Amphipoda $\cdot$ Microphallidae $\cdot$ Microcalorimetry $\cdot$ Thermal tolerance $\cdot$ Freezing tolerance $\cdot$ Parasitism

Resale or republication not permitted without written consent of the publisher

\section{INTRODUCTION}

The amphipod Corophium volutator (Pallas, 1766) is a well-known inhabitant of coastal mudflats of Europe and North America. The studies of several authors have led to a greater understanding of the ecology and physiology of this species. During the last few years, the discussion about population dynamics of $C$. volutator has resumed because of a new aspect: parasitism (Lauckner 1986, 1990). Primarily involved are digenetic trematodes. In shallow water areas of the southern Baltic Sea, for example, C. volutator is used as a second intermediate host by at least 2 microphallid trematode species: Maritrema subdolum (Jägerskiöld 1908) and Levinseniella brachysoma (Creplin 1837) (Reimer 1963). The cercariae of these species emerge

*E-mail: karin.meissner@biologie.uni-rostock.de from the first intermediate host, a gastropod of the genus Hydrobia for example, and seek out the next host, a crustacean. There the cercariae develop into metacercariae and form metacercarial cysts of different sizes. In a single $C$. volutator, for instance, up to 100 metacercarial cysts can be found (Fig. 1). The life cycle of these digenetic trematodes is completed when the final host, a sea bird or wader, feeds on infested $C$. volutator specimens.

The lowest values of the relative infestation intensity and prevalence among Corophium volutator specimens generally were recorded in May and June, when the offspring of individuals that had overwintered predominated within the population (Bick 1994, Meißner \& Bick 1997). Thereafter, increasing numbers of individuals were infested with increasing frequency until autumn (Meißner \& Bick 1997). A statistical analysis revealed that $C$. volutator with high infestation inten- 


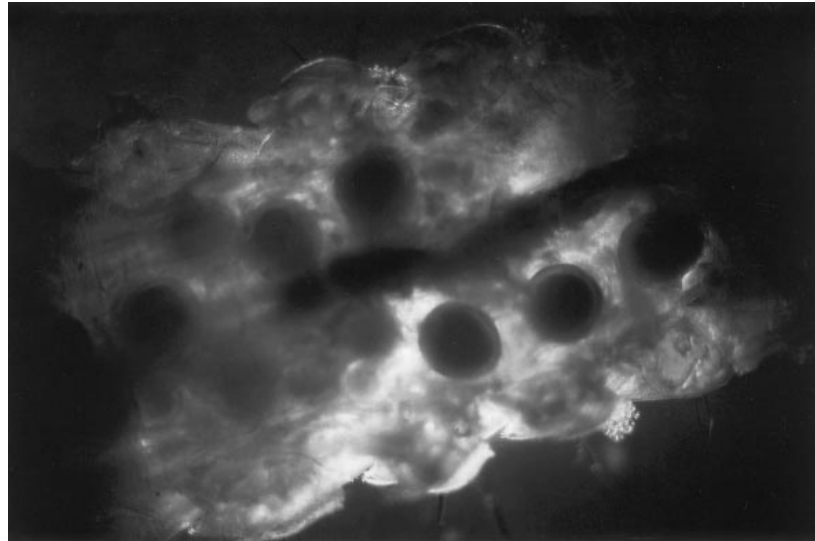

Fig. 1. Corophium volutator. Metacercarial cysts in the body cavity (thoracic region, appendages removed)

sities (14 to 22 cysts ind. ${ }^{-1}$ ) were distinctly less common in September than theoretically expected (infestation assumed to be a random event and subsequent infestations independent of previous ones) (Meißner \& Bick 1997). Laboratory studies showed that severe infestation through microphallid trematodes (>60 metacercarial cysts or $\sim 40$ not yet encysted metacercariae) is detrimental to $C$. volutator and finally leads to the death of the host (Jensen et al. 1998, Meißner \& Bick 1999a). Moreover, these parasites are possibly responsible for mass mortality events in $C$. volutator populations (Lauckner 1987, Jensen \& Mouritsen 1992, Meißner \& Bick 1997). However, there is still little known about the kind of impairment that occurs. Metacercarial cysts can be found in almost every part of the body, but particulary in the posterior thorax region (Mouritsen \& Jensen 1997). Histological examinations of infested C. volutator revealed that the cysts are located in the mixocoel without any real contact to the host's organs (R. Bochert, Univ. Rostock, pers. comm.). Galaktionov et al. (1996) investigated the developmental changes in the tegument of 4 microphallid species in the second intermediate host and concluded that recently encysted metacercaria of the species Levinseniella brachysoma and Maritrema subdolum absorb nutrients and other substances from the haemolymph of their host Gammarus oceanicus during a period of up to $35 \mathrm{~d}$. It is also conceivable that metacercarial cysts exert a mechanical impact on the tissues and organs of the host.

With this background knowledge, it is possible that differences exist in the physiology and autecology of infested and non-infested Corophium volutator. To test this assumption, we conducted measurements of metabolic heat dissipation as a measure of metabolic activity in C. volutator specimens with different infestation intensities. Metabolic heat loss was measured at different temperatures and oxygen combinations to examine the possible synergistic effects of temperature, oxygen content of the water and infestation intensity on metabolic activity. Apart from effects on the metabolism, an impact on the general physiological fitness of the host is conceivable, possibly reflected in reduced tolerance towards extreme environmental conditions. As an inhabitant of intertidal and shallow water areas, C. volutator is exposed to great diurnal and seasonal fluctuations of temperature. Water temperature in the summer is usually above $30^{\circ} \mathrm{C}$ during the day in our investigation area, whereas in the winter the water is frozen solid to the bottom for several weeks. Hence, freezing and thermal stress tolerance experiments are relevant observations concerning potential consequences of trematode infestation.

\section{MATERIAL AND METHODS}

Collection and storage of Corophium volutator. The Corophium volutator specimens used in the experiments were collected in a shallow water area in the southern part of the Mecklenburger Bucht, Baltic Sea. The collected crustaceans were held in aerated aquaria with seawater and heat-treated sediment from the biotope for about $4 \mathrm{wk}$. In addition, mudsnails of the genus Hydrobia were placed in some of the aquaria with $C$. volutator to induce higher microphallid infestation intensities of the crustacean. Sieved sediment (200 $\mu \mathrm{m}$ mesh) from the uppermost sediment layer in the biotope was added into the aquaria to induce the growth of algae on the sediment layer and glass panes of the aquaria, serving as foodstuff for the specimens. In addition a few $\mathrm{ml}$ of a culture solution of the diatom Thalassiosira fluviatilis were introduced into the aquaria weekly.

After this period, Corophium volutator was transferred to the adaptation aquaria and kept under constant conditions for at least $2 \mathrm{wk}$ until the start of the experiments (Table 1). During this adaptation period, storage conditions were identical to the ones described above, but without the mudsnails.

Experimental design. Metabolic heat loss measurements: Metabolic heat loss in Corophium volutator was measured by direct microcalorimetry using a TAM (Thermal Activity Monitor 2277, Thermometric AB, Sweden). Perfusion cells with $4 \mathrm{ml}$ ampoule in twin arrangement (1 sample and 1 reference system for each channel) were used. Thermal calibration was performed using the internal calibration unit of the TAM. The specimen chambers were prepared with a thin layer of washed, sieved and ashed $\left(500^{\circ} \mathrm{C}\right)$ sediment from the sample location. Continous water flow (average of $14 \mathrm{ml} \mathrm{h}^{-1}$ ) was applied by means of a peristaltic pump. To minimize bacterial growth and contamination, the water was filtered before use $(0.45 \mu \mathrm{m}$ mem- 
Table 1. Laboratory conditions during the adaptation period of Corophium volutator before the start of the experiments

\begin{tabular}{|lccccc|}
\hline Experiment & $\begin{array}{c}\text { Date of specimen } \\
\text { collection }(\mathrm{mo} / \mathrm{yr})\end{array}$ & $\begin{array}{c}\text { Temperature } \\
\left({ }^{\circ} \mathrm{C}\right)\end{array}$ & Light period L/D & $\begin{array}{c}\text { Salinity } \\
(\%)\end{array}$ & Adaptation period \\
\hline Freezing tolerance & $10 / 96$ & 3 & $11 \mathrm{~h} / 13 \mathrm{~h}$ & 13.3 & $4 \mathrm{wk}$ \\
Thermal tolerance & $7 / 97$ & 20 & $14 \mathrm{~h} / 10 \mathrm{~h}$ & 14 & $\geq 2 \mathrm{wk}$ \\
Metabolic 1 & $3 / 98-4 / 98$ & 10 & $12 \mathrm{~h} / 12 \mathrm{~h}$ & 14 & $\geq 2 \mathrm{wk}$ \\
heat loss 2 & $9 / 96-2 / 97$ & 15 & $14 \mathrm{~h} / 10 \mathrm{~h}$ & 14 & $\geq 2 \mathrm{wk}$ \\
& $7 / 97-2 / 98$ & 19 and 25 & $14 \mathrm{~h} / 10 \mathrm{~h}$ & $14 \quad 2 \mathrm{wk}+$ \\
& & & & $4 \mathrm{~d}\left(25^{\circ} \mathrm{C}\right)$ \\
\end{tabular}

brane filter). Defined oxygen saturation in the water was generated by controlled flow of air and nitrogen (combined oxygen-sensor-valve-gear unit; Oxyguard 1, Birkerød, Denmark).

Each measurement was carried out on single adult Corophium volutator in total darkness. Measuring conditions were checked by establishing baselines over at least $12 \mathrm{~h}$ before and after each experiment. After inserting the amphipod into the measuring system, a $7 \mathrm{~h}$ period was excluded from data analysis, after which metabolic activity became stable. A specimen was measured at a single temperature $\left(10,15\right.$ or $\left.25^{\circ} \mathrm{C}\right)$, but exposed to different levels of oxygen content of water $(100,50,35 \%$ air saturation corresponding to approximately $20.8,10.4,7.3 \mathrm{kPa} \mathrm{O}$ respectively; at $10^{\circ} \mathrm{C}$ measurement only at $100 \%$ air saturation). Oxygen partial pressure was maintained for at least $6 \mathrm{~h}$. After changing the oxygen partial pressure, stable metabolic activity readjusted within $3 \mathrm{~h}$. However, this period was not included in the data analysis. Metabolic activity was continously measured throughout each experiment. At the end of the experiment, the specimen was removed from the ampoule, measured and dissected to determine the number of trematode metacercariae.

The calorimetric signals were recorded and analysed using an analog-digital converter and software (Baumbach, Berlin, Germany). The thermograms were analysed as follows: (1) determination of the heat flux $\left(\mathrm{mJ} \mathrm{h} \mathrm{h}^{-1} \mathrm{mg}^{-1}\right.$ fresh weight) for a measurement period at distinct experimental conditions (temperature, oxygen). (2) Analysis of specimen activity (locomotory) by calculating ratios between periods of enhanced activity (thermogram peaks) and periods of routine activity for each set of measurement conditions and specimen (manual selection of the peaks and intervals).

activity ratio $=$ total time of periods of elevated activity/ total time of periods of routine activity

Thermal tolerance experiments: For the thermal tolerance experiments a thermostat (Lauda RMS) was used. The jars were filled with $15 \mathrm{ml}$ of seawater from the biotope and subsequently placed in a temperaturecontrolled bath. After reaching the experimental tem- perature $\left(36,36.5\right.$ or $\left.38.5^{\circ} \mathrm{C}\right)$, a single Corophium volutator specimen was placed in the jar. At the end of an incubation time of $10 \mathrm{~min}$ for each temperature, the specimen was immediately removed from the jars and placed in a recovery aquarium under the original adaptation conditions.

The state of activity of Corophium volutator was assessed after $24 \mathrm{~h}$. Two different states were distinguished: (1) normal behaviour or slight difficulties in swimming and burrowing; reaction to contact stimulus was still observable. (2) Slight movements of the antennae or the most distal parts of the peraeopods or no activity at all; no reaction to contact stimulus.

All specimens were measured, sexed and subsequently dissected under the microscope to ascertain the number of larval trematodes. Juveniles and eggcarrying females were excluded from the experiments. The Corophium volutator specimens were divided into 2 test groups: slightly infested specimens and heavily infested specimens. This division was made on the following bases: according to body length $C$. volutator specimens were assigned to different size classes $(4$, $4.5,5 \mathrm{~mm}, \ldots$ ); subsequently mean infestation intensity within the different size classes was calculated. All specimens with infestation intensities lower than the mean infestation intensity of the respective size class were assigned to test group (1), all other specimens with higher infestation intensities to test group (2). With this procedure, it was possible to take the different sizes of the crustaceans into consideration. Noninfested specimens constituted the control group.

Freezing tolerance experiments: Small jars, filled with $10 \mathrm{ml}$ seawater from the biotope (13.3\%), were placed in a refrigerated water/glycerine bath (bath temperature $-10^{\circ} \mathrm{C}$ ) for a few minutes. The experiment started when the specimen was placed in the jar. A few crystals of ice were immediately added to freeze the water. At the end of a defined incubation time $(6,8,10$, $12.5,15,20$ and $30 \mathrm{~min})$, the jars were removed from the bath. The moment the ice started to melt, the still frozen Corophium volutator was placed in a recovery aquarium (same conditions as in the adaptation period). After $24 \mathrm{~h}$ the state of activity of $C$. volutator 
was assessed. Again, 2 states were distinguished: (1) specimens were able to move their pleopods, but sometimes had difficulties in swimming and burrowing; reaction to contact stimulus was observable; sometimes black spots occurred on the body. (2) No swimming and burrowing; no reaction to contact stimulus; the specimens' bodies often were black-spotted or entirely black.

All crustaceans were measured, sexed and than subjected to parasitological examination. Corophium volutator were assigned to 1 of the 2 test groups: (1) slightly infested specimens and (2) heavily infested specimens on the same principle as in the thermal tolerance experiments. Non-infested adult specimens were only rarely found in autumn (date of specimen collection); thus a control group was not constituted.

Parasitological examination: Previous studies indicated that in the course of $1 \mathrm{yr}, 10$ to $90 \%$ of the Corophium volutator in this area are infested by 2 species of trematode parasites, Maritrema subdolum and Levinseniella brachysoma (Digenea) (Meißner \& Bick, 1997). The preparation of the metacercariae from the cyst is very time-consuming, and hence not feasible for a great number of cysts. But the cysts of these species differ distinctly in size: cysts with multi-layered cyst walls of the species $L$. brachysoma are $\sim 400 \mu \mathrm{m}$ in diameter, and in the case of M. subdolum, $\sim 220 \mu \mathrm{m}$ in diameter. Hence, it was possible to distinguish between 2 different types of cysts, corresponding to the cyst size of M. subdolum and L. brachysoma. Some cysts were prepared for determination of the metacercaria they contained. However, it cannot be ruled out that C. volutator were also infested by other trematode species.

It seems appropriate here to define the meanings of some parasitological terms used in the present study (according to Margolis et al. 1982; amended): (1) Prevalence: number of individuals of an infested host species divided by the number of hosts examined; (2) Infestation intensity: number of parasites in each infested host in a sample; (3) Mean infestation intensity: mean number of parasites per infested host; (4) Relative infestation intensity: mean number of parasites per host examined.

Statistics: Influence of temperature, oxygen and infestation intensity on metabolic heat loss and activity patterns (activity ratio) was analysed by multiple regression analysis or analysis of variance (ANOVA) using STATEASY (J. Lozán, Hamburg, Germany) and SPSS (SPSS Inc., USA) software. The lethal time and temperature ( $t_{\mathrm{L} 50}$ and $T_{\mathrm{L} 50}$, respectively) values for both test groups in the freezing and thermal tolerance experiments were evaluated by a Probit analysis (Maximum Likelihood method) using STATEASY. The difference between the $t_{\mathrm{L} 50}$ values was analysed after Natrella (1963).

\section{RESULTS}

\section{Measurement of metabolic heat loss}

Specimens used in the experiments were infested by at least 2 parasite species, Maritrema subdolum and Levinseniella brachysoma. Metacercarial cysts of the species M. subdolum predominated ( $88.4 \%)$.

Corophium volutator exhibited various metabolic activity patterns which can be described as a composition of periods, differing in length, of enhanced activity (presumably due to increased locomotory activity) and of routine activity (Fig. 2). Specimens dissipated metabolic heat on an approximately steady level, or metabolic heat flux varied more or less rhythmically. There was no obvious relation between infestation intensity and metabolic activity patterns. A significant correlation between infestation intensity and metabolic heat flux of $C$. volutator was found in 2 cases only, at $10^{\circ} \mathrm{C}, 100 \%$ oxygen saturation $(y=$ $0.795+0.19 x, r=0.477, \mathrm{p}=0.05)$ and at $15^{\circ} \mathrm{C}, 50 \%$ oxygen saturation $(y=0.95+0.053 x, r=0.743, p=$ 0.05 ) (Fig. 3). Metabolic heat flux at comparable oxygen levels was positively correlated with temperature, with highest amounts at $25^{\circ} \mathrm{C}$ (Table 2). At all examined temperatures, hypoxia down to $35 \%$ oxygen content in the water did not significantly affect metabolic heat flux (Table 2). C. volutator was more active with rising temperature, but an effect of infestation intensity on activity was not observed (Fig. 4). The results of the statistical analysis are shown in Table 3.

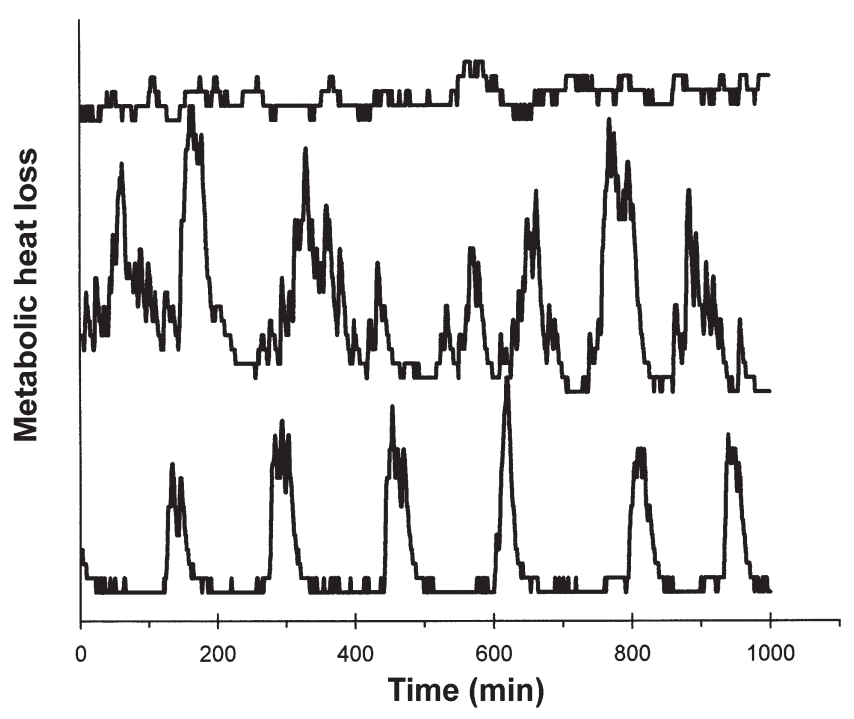

Fig. 2. Examples of different metabolic heat loss patterns from 3 Corophium volutator at $10^{\circ} \mathrm{C} / 100 \%$ oxygen content in the water 


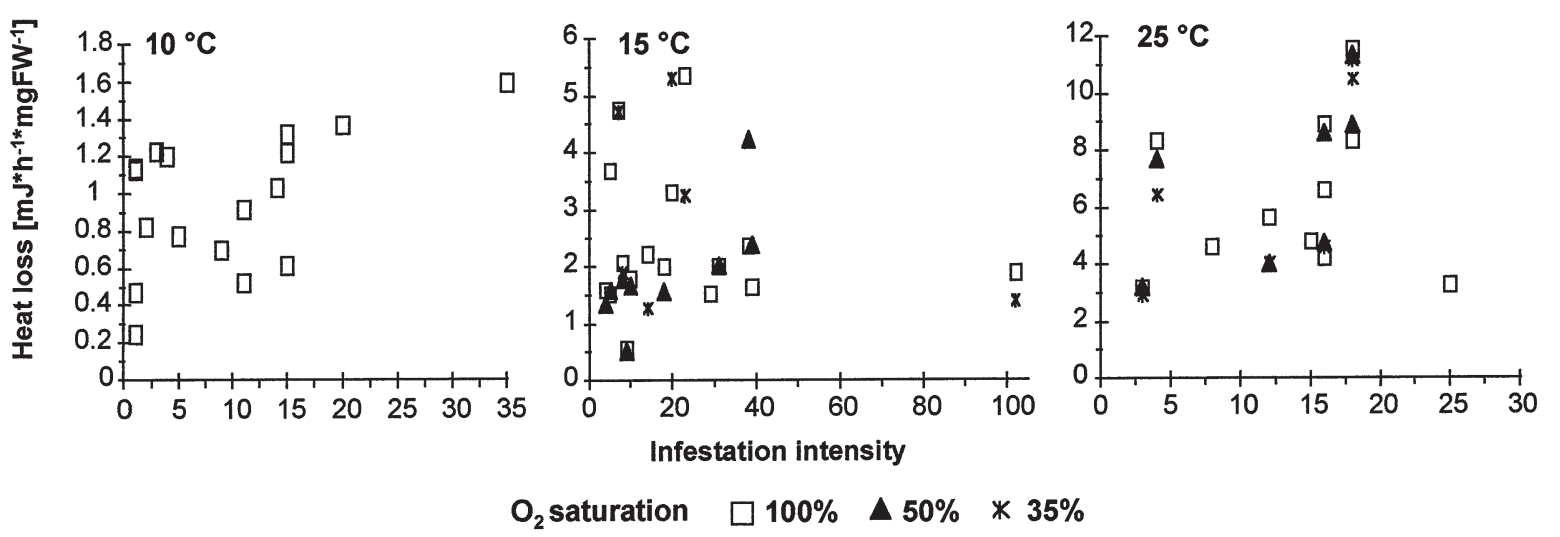

Fig. 3. Heat loss ( $\mathrm{mJ} \mathrm{h}^{-1} \mathrm{mg}^{-1}$ fresh weight) dependent on infestation intensity from Corophium volutator ascertained by direct microcalorimetry. Body length of the specimens was $6.11 \mathrm{~mm}( \pm 0.47 \mathrm{SD})\left(10^{\circ} \mathrm{C}\right), 5.4 \mathrm{~mm}( \pm 0.98 \mathrm{SD})\left(15^{\circ} \mathrm{C}\right)$ and $5.63 \mathrm{~mm}$ $( \pm 0.58 \mathrm{SD})\left(25^{\circ} \mathrm{C}\right)$

Table 2. Heat loss ( $\mathrm{mJ} \mathrm{h}^{-1} \mathrm{mg}^{-1}$ fresh weight) from Corophium volutator specimens with different infestation intensities ascertained by direct microcalorimetry at varying temperatures and oxygen conditions; $\mathrm{N}=1$ if not mentioned

\begin{tabular}{|c|c|c|c|c|c|c|c|c|c|c|c|c|c|c|}
\hline \multirow{2}{*}{$\begin{array}{l}\text { Infestation } \\
\text { intensity }\end{array}$} & \multicolumn{2}{|c|}{$-\left(10^{\circ} \mathrm{C}\right)-$} & \multirow[b]{2}{*}{$100 \% \mathrm{O}_{2}$} & \multirow[b]{2}{*}{$\mathrm{N}$} & \multirow{2}{*}{$\begin{array}{c}-\left(15^{\circ} \mathrm{C}\right) \\
50 \% \mathrm{O}_{2}\end{array}$} & \multirow[b]{2}{*}{$\mathrm{N}$} & \multirow[b]{2}{*}{$35 \% \mathrm{O}_{2}$} & \multirow[b]{2}{*}{$\mathrm{N}$} & \multirow[b]{2}{*}{$100 \% \mathrm{O}_{2}$} & \multirow[b]{2}{*}{$\mathrm{N}$} & \multirow{2}{*}{$\begin{array}{l}-25^{\circ} \mathrm{C} \\
50 \% \mathrm{O}_{2}\end{array}$} & \multirow{2}{*}{$\mathrm{N}$} & \multirow[b]{2}{*}{$35 \% \mathrm{O}_{2}$} & \multirow[b]{2}{*}{$\mathrm{N}$} \\
\hline & $100 \% \mathrm{O}_{2}$ & $\mathrm{~N}$ & & & & & & & & & & & & \\
\hline 1 & $0.74 \pm 0.46$ & 4 & & & & & & & & & & & & \\
\hline 2 & 0.82 & & & & & & & & & & & & & \\
\hline 3 & $1.22 \pm 0.0$ & 2 & & & & & & & 3.17 & & 3.24 & & 2.94 & \\
\hline 4 & 1.2 & & 1.59 & & 1.35 & & & & 8.32 & & 7.7 & & 6.48 & \\
\hline 5 & 0.78 & & 3.7 & & 1.59 & & & & & & & & & \\
\hline 7 & & & 4.75 & & & & 4.72 & & & & & & & \\
\hline 8 & & & $2.07 \pm 0.01$ & 2 & 1.77 & & 1.91 & & 4.61 & & & & & \\
\hline 9 & 0.7 & & 0.56 & & 0.51 & & & & & & & & & \\
\hline 10 & & & 1.78 & & 1.67 & & & & & & & & & \\
\hline 11 & $0.72 \pm 0.28$ & 2 & & & & & & & & & & & & \\
\hline 12 & & & & & 1.58 & & & & 5.62 & & 4.07 & & 4.03 & \\
\hline 14 & 1.03 & & 2.22 & & & & 1.27 & & & & & & & \\
\hline 15 & $1.05 \pm 0.38$ & 3 & & & & & & & 4.82 & & & & & \\
\hline 16 & & & & & & & & & $6.58 \pm 2.32$ & 3 & $6.7 \pm 2.7$ & 2 & 4.61 & \\
\hline 18 & & & 1.99 & & & & & & $9.94 \pm 2.24$ & 2 & $10.12 \pm 1.69$ & 2 & $10.85 \pm 0.48$ & 32 \\
\hline 20 & 0.14 & & 3.3 & & & & 5.31 & & & & & & & \\
\hline 23 & & & 5.35 & & & & 3.26 & & & & & & & \\
\hline 25 & & & & & & & & & 3.26 & & & & & \\
\hline 29 & & & 1.51 & & & & & & & & & & & \\
\hline 31 & & & 1.99 & & 2.02 & & & & & & & & & \\
\hline 35 & 1.59 & & & & & & & & & & & & & \\
\hline 38 & & & 2.37 & & 4.23 & & & & & & & & & \\
\hline 39 & & & 1.63 & & 2.38 & & & & & & & & & \\
\hline 102 & & & 1.89 & & & & 1.41 & & & & & & & \\
\hline
\end{tabular}

\section{Thermal tolerance experiments}

Most Corophium volutator used in the thermal tolerance experiments were assigned to test group (1), slightly infested specimens $(\mathrm{N}=104)$. Mean infestation intensity among these specimens was 2.13 ( $\pm 1.25 \mathrm{SD})$. In specimens of test group (2), heavily infested specimens $(\mathrm{N}=87)$, an average of 15.13 metacercarial cysts ( $\pm 7.9 \mathrm{SD})$ was found. Metacercarial cysts of the species Maritrema subdolum predominated (95.3\%). A total of
72 C. volutator specimens were non-infested and constituted the control group.

Concerning incubation temperature, almost no differences were observed in the survival rates between the test groups, except at $37.5^{\circ} \mathrm{C}$ (Table 4 ). The $T_{\mathrm{L} 50}$ values were $37.32^{\circ} \mathrm{C}( \pm 0.12 \mathrm{SD})$ (test group 1$), 37.25^{\circ} \mathrm{C}$ $( \pm 0.14 \mathrm{SD})$ (test group 2$)$ and $37.51^{\circ} \mathrm{C}( \pm 0.16 \mathrm{SD})$ (control group). Thus, the level of metacercarial cyst infestation did not affect the thermal tolerance of Corophium volutator. 


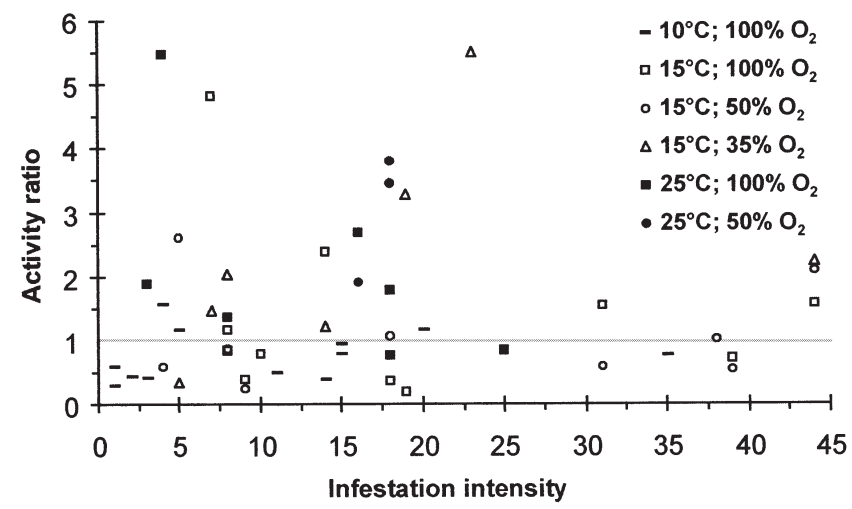

Fig. 4. Activity ratios of Corophium volutator dependent on infestation intensity evaluated from the thermograms at different experimental conditions

Table 3. Results of the statistical analysis (significance of $F$ )

\begin{tabular}{|lcc|}
\hline & $\begin{array}{c}\text { Metabolic heat loss } \\
\text { (ANOVA) }\end{array}$ & $\begin{array}{c}\text { Activity ratio } \\
\text { (Mult. Regr. Analysis) }\end{array}$ \\
\hline Infestation intensity & 0.62 & 0.202 \\
Temperature & $0.0^{\mathrm{a}}$ & $0.012^{\mathrm{a}}$ \\
Oxygen content & 0.96 & 0.246 \\
${ }^{\text {a }}$ Significance of $F_{\text {; }}$ significant influence on parameter \\
\hline
\end{tabular}

\section{Freezing tolerance experiments}

In the freezing tolerance experiments, 169 Corophium volutator were assigned to test group (1) and 111 to test group (2). The slightly infested specimens harboured $2.63( \pm 1.85 \mathrm{SD})$ metacercariae on average in their body cavities, whereas $11( \pm 6.3 \mathrm{SD})$ metacercariae were found in heavily infested specimens. The proportion of Maritrema subdolum cysts was $94 \%$.

There was a significant difference between the 2 test groups in respect to the survival rate (Fig. 5). At the same incubation time, more heavily infested than slightly infested specimens generally survived. The
$t_{\mathrm{L} 50}$ value of test group (1) was $10.21 \mathrm{~min}( \pm 0.76 \mathrm{SD})$, for test group (2) we ascertained $t_{\mathrm{L} 50}=13.15 \mathrm{~min}( \pm 1.25$ $\mathrm{SD})$. The difference of $t_{\mathrm{L} 50}$ between the test groups was significant $(z=2.0)$.

\section{DISCUSSION}

Ecophysiological investigations on Corophium volutator are well documented. Studies exist on the effects of temperature and salinity (McLusky 1967, 1968, Mills \& Fish 1980, Holmstrom et al. 1981, Meadows \& Ruagh 1981), osmotic and ionic regulation (McLusky 1968, Taylor 1985), effects of hypoxia, sediment sulphide and metals (Meadows et al. 1981, Eriksson \& Weeks 1994, Bat et al. 1998) as well as studies on seasonal changes of energy values and lipid content in C. volutator (Boates \& Smith 1979, Dobrzycka \& Szaniawska 1993). Unfortunately, in none of these studies were infestation or infection by parasites taken into consideration, although it is known, for example, that adult $C$. volutator are infested by trematodes throughout the year.

Our investigations measured metabolic heat loss by direct microcalorimetry, a widely accepted method for the evaluation of the general metabolism of organisms (e.g. Widdows 1987). Our measurements revealed that metacercaria infestation has a minor effect on metabolic heat loss of Corophium volutator (Table 2). In just 2 cases under the experimental conditions, $10^{\circ} \mathrm{C} / 100 \%$ $\mathrm{O}_{2}$ and $15^{\circ} \mathrm{C} / 50 \% \mathrm{O}_{2}$, a positive correlation between heat loss and the number of metacercarial cysts was noted. Consequently, the impact of the present metacercaria infestations on the host metabolism seems to be not severe.

According to the results of the thermal tolerance experiments, the level of metacercarial cyst infestation does not appear to compromise the thermal tolerance of Corophium volutator (Table 4). This result is interesting, taking into account that 15 metacercarial cysts (mean infestation intensity of test group 2) take up

Table 4. Survival rates of Corophium volutator specimens at different incubation temperatures. Incubation time $=10 \mathrm{~min} ; \mathrm{S}=$ $14 \%$. Test group 1: slightly infested specimens; test group 2: heavily infested specimens. $T_{\mathrm{L} 50}$ : lethal temperature

\begin{tabular}{|c|c|c|c|c|c|c|c|c|c|}
\hline \multirow{2}{*}{$\begin{array}{l}\text { Temperature } \\
\left({ }^{\circ} \mathrm{C}\right)\end{array}$} & \multicolumn{3}{|c|}{ Test group 1} & \multicolumn{3}{|c|}{ Test group 2} & \multicolumn{3}{|c|}{ Control group } \\
\hline & $\mathrm{N}_{\text {survived }}$ & $\mathrm{N}_{\text {total }}$ & Survival rate $(\%)$ & $\mathrm{N}_{\text {survived }}$ & $\mathrm{N}_{\text {total }}$ & Survival rate $(\%)$ & $\mathrm{N}_{\text {survived }}$ & $\mathrm{N}_{\text {total }}$ & Survival rate $(\%)$ \\
\hline 36 & 11 & 11 & 100 & 16 & 17 & 94.1 & 18 & 20 & 90 \\
\hline 36.5 & 3 & 3 & 100 & 11 & 11 & 100 & - & - & \\
\hline 37 & 23 & 36 & 63.8 & 9 & 13 & 69.2 & 11 & 16 & 68.75 \\
\hline 37.5 & 5 & 8 & 62.5 & 6 & 16 & 37.5 & 9 & 12 & 75 \\
\hline 38 & 4 & 26 & 15.4 & 2 & 16 & 12.5 & 1 & 10 & 10 \\
\hline 38.5 & 0 & 20 & 0 & 0 & 14 & 0 & 0 & 14 & 0 \\
\hline \multirow[t]{2}{*}{$\sum$} & & 104 & & & 87 & & & 72 & \\
\hline & & & $T_{\mathrm{L} 50}=37.32^{\circ} \mathrm{C}$ & & & $T_{\mathrm{L} 50}=37.25^{\circ} \mathrm{C}$ & & & $T_{\mathrm{L} 50}=37.51^{\circ} \mathrm{C}$ \\
\hline
\end{tabular}




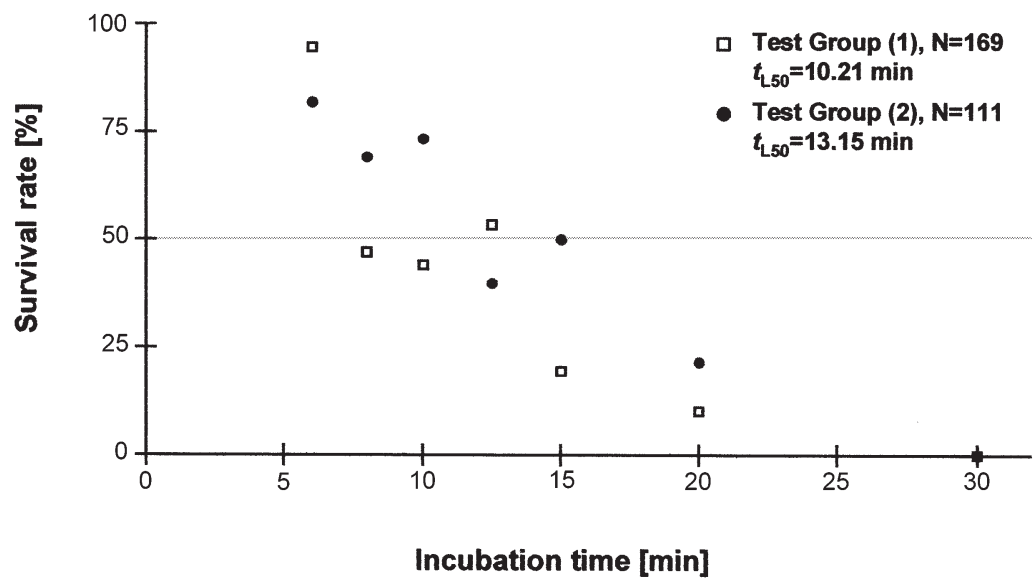

Fig. 5. Survival rate dependent on incubation time of Corophium volutator exposed to freezing. Test group (1): slightly infested specimens, body length = $5.1 \mathrm{~mm}( \pm 0.64 \mathrm{SD})$; test group (2): heavy infested specimens, body length $=$ $5.29 \mathrm{~mm}( \pm 0.65 \mathrm{SD}) . \mathrm{S}=13.3 \%$. $t_{\mathrm{L} 50}$ : lethal time

quite a considerable space in the body cavity of $C$. volutator and hence should represent a burden. It does, however, indicate a good adaptation of the parasite. In the life cycle of Digenea, the second intermediate host is used as a vector, and hence for the completion of the life cycle the survival of $C$. volutator is necessary until predation by the final host, various sea birds and waders.

Similar studies of host metabolism and high temperature tolerance have been carried out mainly on molluscan hosts. Becker \& Lamprecht (1977) and Becker (1980) found significantly higher heat production in Biomphalaria glabrata snails infected by Schistosoma mansoni in comparison to their uninfected counterparts and interpreted restricted movements of infected snails as compensation for their higher basal metabolism. For the same parasite/host relation, Lee \& Cheng (1971) recorded an increasing oxygen consumption rate with the duration of infection. In the case of Nassarius reticulatus (Tallmark \& Norrgren 1976) and Cerastoderma edule (Lauckner 1983), larval trematode infection has been shown to cause increased mortality at high temperatures, but for Cerithidea californica Sousa \& Gleason (1989) found that parasitic infection does not appear to compromise the thermal tolerance of the host. However, when comparing these studies with our results one should bear in mind that molluscs are mainly used as the first intermediate host by digenetic trematodes. Larval trematodes such as rediae or sporocysts probably exert a completely different impact on their hosts. From this point of view, we also have to distinguish between 2 different metacercarial stages in Corophium volutator: (1) the cercaria penetrates the host's cuticule and spends periods, from several hours up to a number of days, as free-moving metacercaria until reaching their final location for encystment (Meissner \& Bick 1999b). There the formation of a multi-layered cyst wall begins. The thin primary cyst wall presumably is not impervious to nutrient transport (Galaktionov et al. 1996). (2) The metacercaria is enclosed in a multilayered capsule resistant to chemical transport (Galaktionov et al. 1996). In the course of the first developmental step, the metacercaria attains its maximum size and completes the development of organ systems. It is very likely that this first developmental period, apart from the penetration itself, is much more exhausting for the host than the second one. It finishes $30 \mathrm{~d}$ post infection in the case of Maritrema subdolum and M. claviformis and $42 \mathrm{~d}$ post infestion in Levinseniella brachysoma (all Microphallidae) (Galaktionov 1993). The specimens of $C$. volutator used in our experiments had been acclimated in aquaria without Hydrobia spp. for at least 2 wk before the start of the experiments. This means that most of the metacercariae harboured by the specimens had already passed the developmental period in which they absorb nutrients from their host. Possibly, if we had simulated massive occurrence of cercaria by only using recently infested C. volutator in our experiments, we would have found modifications of the metabolism or reduced thermal tolerance in infested hosts.

The results of the freezing tolerance experiments imply an advantage for heavily infested specimens in comparison to slightly infested ones. Regarding the lethal times $\left(t_{\mathrm{L} 50}\right)$ it must be considered that the experiments simulated extreme environmental conditions. Attention should be turned to the difference between the 2 test groups. Based on our assumption at the start of the experiments, that Corophium volutator has a reduced fitness due to the parasite load, we had expected opposite results. However, the advantage for the trematode is obvious and could be regarded as an overwintering strategy. Infestation of $C$. volutator occurs until autumn (Meißner \& Bick 1997). Then the trematodes can safely overwinter as metacercarial cysts in C. volutator and in spring, on arrival of migratory birds which feed on $C$. volutator, the parasite cycle starts again. However, this is just speculation and nothing is known about the impact of the parasite on the physiology of the host. In addition, little information exists concerning freezing tolerance mechanisms of $C$. volutator. In laboratory studies on the temperature preference of this species, an avoidance of low temperatures was found (Meadows \& Ruagh 1981). Holmstrom et al. (1981) concluded from their results that $C$. 
volutator might not be expected to have physiological adaptations. They did not find any accumulation of effective cryodepressants in the haemolymph and no seasonal differences between whole body freezing points of males and females, although they observed increased low temperature tolerance in the winter population. Further studies will be needed to broaden our knowledge regarding this problem.

Parasitism is often accompanied by various changes of behaviour (Holmes \& Bethel 1972, Helluy \& Holmes 1990, Poulin 1995). Mouritsen \& Jensen (1997) found increased surface activity of infested Corophium volutator. During our measurements, the activity patterns of the $C$. volutator specimens in the specimen chambers of the TAM differed strongly. To enable a comparison of the behaviour between the individuals, activity ratios were calculated from the thermograms. According to these calculations, the observations of Mouritsen \& Jensen (1997) cannot be confirmed, but it must be conceded that the behaviour of $C$. volutator in the specimen chamber of the TAM might be very different from that under natural conditions.

Looking at the results of our investigations, we have to conclude that metacercaria infestation of the intensities studied does not affect the responses of Corophium volutator to abiotic stress. Average infestation intensities appear not to compromise the host. Under normal field conditions, changes of metabolic activity or reduced tolerance towards thermal stress and freezing as a result of metacercaria infestation should not be responsible for mass mortality events observed in the field. However, at higher infestation intensities such effects are possible. Previous studies indicate that $C$. volutator is able to accumulate more than 60 encysted and further non-encysted metacercariae before it dies (Meißner \& Bick 1999a). But such levels of infestation are reached under exceptional circumstances only (Meissner \& Bick 1999b). It appears that the penetration of many cercariae at the same time, induced by high cercariae densities in the field, is much more harmful. As discussed above, earlier developmental stages of metacercariae might exert a much more obvious impact on the host. In laboratory studies $C$. volutator exposed to $200 \mathrm{M}$. subdolum cercaria in a small dish $\left(9.6 \mathrm{~cm}^{2}\right)$ died within $1.6 \mathrm{~d}$. On average, 40 nonencysted cercariae were found in dead specimens (Meißner \& Bick 1999a). In this case the causes of death might be very complex and still have to be investigated.

Acknowledgements. This study is part of a topic supported by the German Ministry of Education and Research under grant No. 03F0175A. We acknowledge the comments and suggestions of Dr Andreas Bick and Dr Christopher M. Hawkins as well as 2 anonymous reviewers.

\section{LITERATURE CITED}

Bat L, Raffaelli D, Marr IL (1998) The accumulation of copper, zinc and cadmium by the amphipod Corophium volutator (Pallas). J Exp Mar Biol Ecol 223:167-184

Becker W (1980) Microcalorimetric studies in Biomphalaria glabrata: the influence of Schistosoma mansoni on the basal metabolism. J Comp Physiol B 135:101-105

Becker W, Lamprecht I (1977) Mikrokalorimetrische Untersuchungen zum Wirt-Parasit-Verhältnis zwischen Biomphalaria glabrata und Schistosoma mansoni. Z Parasitenkd 53:297-305

Bick A (1994) Corophium volutator (Corophiidae: Amphipoda) as an intermediate host of larval Digenea - an ecological analysis in a coastal region of the southern Baltic. Ophelia 40(1):27-36

Boates JS, Smith PC (1979) Length-weight relationships, energy content and the effects of predation on Corophium volutator (PALLAS) (Crustacea: Amphipoda). Proc Nat Inst Sci 29:489-499

Dobrzycka A, Szaniawska A (1993) Seasonal changes in energy value and lipid content in a population of Corophium volutator (Pallas, 1766) from the Gulf of Gdansk. Oceanologia 35:61-71

Eriksson SP, Weeks JM (1994) Effects of copper and hypoxia on two populations of the benthic amphipod Corophium volutator (Pallas). Aquat Toxicol 29:73-81

Galaktionov KV (1993) Trematode life cycles as components of ecosystems. Kola Scientific Center Press, Apatity

Galaktionov KV, Malkova II, Irwin SWB, Saville DH, Maguire JG (1996) Developmental changes in the tegument of four microphallid metacercariae in their second (crustacean) intermediate hosts. J Helminthol 70:201-210

Helluy S, Holmes JC (1990) Serotonin, octopamine, and the clinging behavior induced by the parasite Polymorphus paradoxus (Acanthocephala) in Gammarus lacustris. Can J Zool 68:1214-1220

Holmes JC, Bethel WM (1972) Modification of intermediate host behaviour by parasites. Behavioural aspects of parasite transmission. Academic Press, London, p 123-149

Holmstrom WF, Grout BWW, Morgan E (1981) Preliminary observations on the low temperature tolerance of an estuarine amphipod Corophium volutator (Pallas). Cryo Lett 2: 129-134

Jensen KT, Mouritsen KN (1992) Mass mortality in two common soft-bottom invertebrates, Hydrobia ulvae and Corophium volutator - the possible role of trematodes. Helgol Meeresunters 46:329-339

Jensen T, Jensen KT, Mouritsen KN (1998) The influence of the trematode Microphallus claviformis on two congeneric intermediate host species (Corophium): infection characteristics and host survival. J Exp Mar Biol Ecol 227(1):35-48

Lauckner G (1983) Diseases of Mollusca: Bivalvia. In: Kinne O (ed) Diseases of marine animals, Vol II. Biologische Anstalt Helgoland, Hamburg, p 477-961

Lauckner G (1986) Ecological effects of larval trematode infestation on littoral marine invertebrate populations. Int J Parasit 17(2):391-398

Lauckner G (1987) Effects of parasites on juvenile Wadden Sea invertebrates. In: Tougaard S, Asbirk S (eds) Proc of the 5th Int Wadden Sea Symposium. The National Forest and Nature Agency \& the Museum of Fisheries and Shipping, Esbjerg, p 103-121

Lauckner G (1990) Parasiten - ihr Einfluss im Ökosystem Wattenmeer. In: Lozan JL, Lenz W, Rachor E, Watermann B, von Westernhagen H (eds) Warnsignale aus der Nordsee. Verlag Paul Parey, Berlin, p 219-230 
Lee FO, Cheng TC (1971) Schistosoma mansoni: respirometric and partial pressure studies in infected Biomphalaria glabrata. Exp Parasitol 30:393-399

Margolis L, Esch GW, Holmes JC, Kuris AM, Schad GA (1982) The use of ecological terms in parasitolgy (Report of an ad hoc committee of the American Society of Parasitologists). J Parasitol 68(1):131-133

McLusky DS (1967) Some effects of salinity on the survival, moulting, and growth of Corophium volutator (Amphipoda). J Mar Biol Assoc UK 47:607-617

McLusky DS (1968) Aspects of osmotic and ionic regulation in Corophium volutator (PALLAS). J Mar Biol Assoc UK 48: 769-781

Meadows PS, Ruagh AA (1981) Multifactorial analysis of behavioural responses of the amphipod Corophium volutator to temperature-salinity combinations. Mar Ecol Prog Ser 6:183-190

Meadows PS, Deans EA, Anderson JG (1981) Responses of Corophium volutator to sediment sulphide. J Mar Biol Assoc UK 61:739-748

Meißner K, Bick A (1997) Population dynamics and ecoparasitological surveys of Corophium volutator in coastal waters in the Bay of Mecklenburg (southern Baltic Sea). Dis Aquat Org 29:169-179

Meißner K, Bick A (1999a) Mortality of Corophium volutator (Amphipoda) caused by infestation with Maritrema subdolum (Digenea, Microphallidae)-laboratory studies. Dis Aquat Org 35:47-52

Meissner K, Bick A (1999b) Laboratory studies of parasite transmission aspects between Hydrobia spp. (Gastropoda) and Corophium volutator (Amphipoda). Int Rev Hydrobiol 84:61-72

Editorial responsibility: Gareth Harding (Contributing Editor), Dartmouth, Nova Scotia, Canada
Mills A, Fish JD (1980) Effects of salinity and temperature on Corophium volutator and C. arenarium (Crustacea: Amphipoda), with particular reference to distribution. Mar Biol 58:153-161

Mouritsen KN, Jensen KT (1997) Parasite transmission between soft bottom invertebrates: temperature mediated infection rates and mortality in Corophium. Mar Ecol Prog Ser 151:123-134

Natrella MG (1963) Experimental statistics. US Department of Commerce, National Bureau of Standards Handbook 91, Washington, DC

Poulin R (1995) 'Adaptive' changes in the behaviour of parasitized animals: a critical review. Int J Parasitol 25: 1371-1383

Reimer L (1963) Zur Verbreitung der Adulti und Larvenstadien der Familie Microphallidae VIANA, 1924, (Trematoda, Digenea) in der mittleren Ostsee. Z Parasitenkd 23: 253-273

Sousa WP, Gleason M (1989) Does parasitic infection compromise host survival under extreme environmental conditions? The case for Cerithidea californica (Gastropoda: Prosobranchia). Oecologia 80:456-464

Tallmark B, Norrgren G (1976) The influence of parasitic trematodes on the ecology of Nassarius reticulatus (L.) in Gullmar Fjord (Sweden). Zoon 4:149-154

Taylor PM (1985) Water balance in the estuarine crustacean Corophium volutator (Pallas) (Amphipoda). J Exp Mar Biol Ecol 88:21-29

Widdows J (1987) Application of calorimetric methods in ecological studies. In: James AM (ed) Thermal and energetic studies of cellular biological systems. John Wright, Bristol, p 182-215

Submitted: April 20, 1999 ; Accepted: January 7, 2000

Proofs received from author(s): July 24, 2000 